\title{
The role of social determinants in explaining racial/ethnic disparities in perinatal outcomes
}

\author{
Scott A. Lorch ${ }^{1-4}$ and Elizabeth Enlow ${ }^{2}$
}

In the United States, there continue to be significant racial/ethnic disparities in preterm birth (PTB) rates, infant mortality, and fetal mortality rates. One potential mediator of these disparities is social determinants of health, including individual socioeconomic factors; community factors such as crime, poverty, housing, and the racial/ethnic makeup of the community; and the physical environment. Previous work has identified statistically significant associations between each of these factors and adverse pregnancy outcomes. However, there are recent studies that provide new, innovative insights into this subject, including adding social determinant data to population-based datasets; exploring multiple constructs in their analysis; and examining environmental factors. The objective of this review will be to examine this recent research on the association of each of these sets of social determinants on racial/ethnic disparities PTB, infant mortality, and fetal mortality to highlight potential areas for targeted intervention to reduce these differences.

N eonatal and infant mortality remains a significant public health issue in the United States. As of 2010, the United States had a 28 -day neonatal mortality rate of 4.46 per 1,000 live births, a fetal mortality rate of 6.05 per 1,000 live births, and a 1-y mortality rate of 6.14 per 1,000 live births (1). There were significant racial/ethnic disparities in these mortality rates. Compared to non-Hispanic white infants, non-Hispanic black infants have a 2.2-fold higher rate of fetal death and infant mortality during the first year of life, and a 2.45 -fold increased rate of 28 -d neonatal mortality $(1,2)$. One key driver of this disparity in infant mortality rates is the increased risk of preterm birth (PTB) in women of minority racial/ethnic status: black women have a 1.6-fold increase in preterm delivery, and a 2.6fold increase in delivery with a birth weight under $1,500 \mathrm{~g}$ (3).

In order to develop potential interventions to reduce these disparities, it is important to understand the underlying mediators, or causes, for these observed differences. One proposed set of mediating factors is the set of factors known as social determinants of health. Social determinants of health are characteristics that describe how people grow, work, and live, and what their sense of control may be of their environment (4). These factors may adversely affect the health of an individual, or in this case the fetus or newborn infant. Specific groups of determinants used in this manuscript are based on work from the World Health Organization $(5,6)$ and the Centers for Disease Control and Prevention $(7,8)$ and the available literature. These areas include income and other measures of socioeconomic status and wealth; maternal or paternal education; housing status, both individually and of the community someone resides in; the physical environment, including air quality and toxin exposure; and experiences with racism or discrimination, both individually and at the community level as measured through segregation indices. The areas include factors at both the individual level and at the community level (Table 1).

Social determinants of health may affect perinatal outcomes both directly or indirectly. For example, air pollution may induce maternal lung injury leading to hypoxemia in utero, which may result in a small-for-gestational age infant. Crime may directly lead to pediatric injury and possibly higher neonatal or infant mortality. Alternatively, individual or community social factors may lead to either acute stress, inflammation, and higher risk of infection, or chronic stress over the life course of the mother, otherwise known as the weathering phenomenon (9-12). These exposures may start as early as in utero and result in fetal programming for other adverse outcomes, such as obesity or hypertension, as the child ages (13-15). This toxic stress may result in adverse perinatal outcomes (Figure 1).

Much of the current literature on racial/ethnic disparities in perinatal outcome describes the phenomenon without exploring mediating causes for these differences that may be more easily modifiable (16). Many studies that do examine these intermediate steps typically concentrate on only one mediator, without examining the contribution of other potential mediators listed in Table 1 (17). However, there are recent studies that provide new and innovative insights into this subject. These studies add social determinant data to larger population-based datasets, which enables researchers to examine such factors with adequate statistical power to detect racial/ethnic disparities; explore multiple social constructs in these observed disparities; or account for physical and environmental factors in racial/

'Division of Neonatology, The Children's Hospital of Philadelphia, Philadelphia, Pennsylvania; ${ }^{2}$ Department of Pediatrics, The Children's Hospital of Philadelphia and the Perelman School of Medicine at The University of Pennsylvania, Philadelphia, Pennsylvania; ${ }^{3}$ Center for Outcomes Research, The Children's Hospital of Philadelphia, Philadelphia, Pennsylvania; ${ }^{4}$ Leonard Davis Institute of Health Economics, University of Pennsylvania, Philadelphia, Pennsylvania. Correspondence: Scott A. Lorch (lorch@email.chop.edu) Received 17 April 2015; accepted 23 August 2015; advance online publication 11 November 2015. doi:10.1038/pr.2015.199 


\section{Review $\mid$ Lorch and Enlow}

Table 1. Specific social determinants of health to explain racial/ethnic disparities in pregnancy outcomes, by type of factor

\begin{tabular}{|c|c|c|c|c|}
\hline & $\begin{array}{l}\text { Socioeconomic } \\
\text { status and education }\end{array}$ & Housing & $\begin{array}{l}\text { Physical } \\
\text { environment }\end{array}$ & $\begin{array}{l}\text { Experiences with racism } \\
\text { and racial discrimination }\end{array}$ \\
\hline \multirow{3}{*}{$\begin{array}{l}\text { Individual/patient } \\
\text { level }\end{array}$} & Income & \multirow[t]{3}{*}{ Housing insecurity } & & \multirow{3}{*}{$\begin{array}{l}\text { Experience with racism } \\
\text { and racial discrimination }\end{array}$} \\
\hline & Marital status & & & \\
\hline & Insurance status & & & \\
\hline \multirow[t]{3}{*}{ Community level } & Poverty level & Crime & Air quality & \multirow[t]{3}{*}{ Community segregation } \\
\hline & Income & Housing and property damage & Pollution exposure & \\
\hline & Access to health care & $\begin{array}{l}\text { Housing stock, including rentals, } \\
\text { home value, and vacancies }\end{array}$ & Toxin exposure & \\
\hline
\end{tabular}

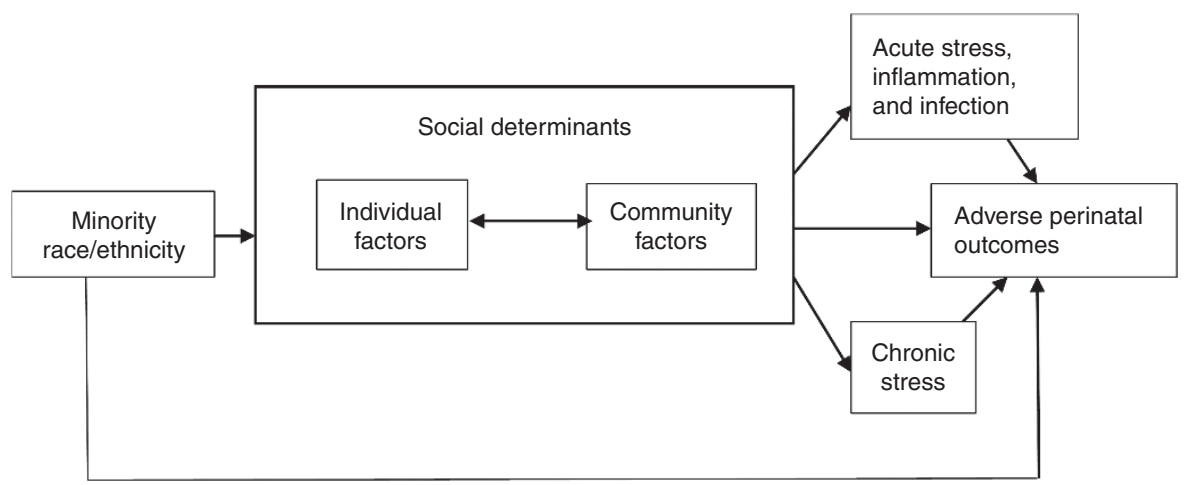

Figure 1. Conceptual framework for the relationship between race/ethnicity, social determinants of health, and adverse perinatal outcomes. The four boxes within the social determinants circle represent specific social determinant constructs. Bi-directional arrows demonstrate the complex interaction of different social determinants in determining the ultimate pregnancy outcome.

ethnic differences in outcomes. The objective of this review is to examine this recent research on the association of each set of social determinants on racial/ethnic disparities in PTB, infant mortality, and fetal mortality to highlight potential areas for targeted intervention to reduce these differences. The review will end with potential future research directions in this field.

\section{PTB}

\section{Individual Factors}

Disparities in PTB persist in the United States and elsewhere, with black women having a 1.6-fold increase in preterm delivery, and a 2.6-fold increase in delivery with a birth weight under $1,500 \mathrm{~g}$ (3). There have been numerous studies examining the potential mediating effect of many individual level social determinants of health presented in Table 1 on this differential risk of PTB. These individual level factors include receipt of welfare as a proxy for income (18); marital status and education level $(19,20)$; exposure to racism and racial discrimination (21-25); and housing insecurity (26). In each case, inclusion of these factors individually explained some, but not all, of the observed disparities in PTB rates. For the markers of socioeconomic status, education, and experiences with racial discrimination, these studies found a dose-response effect, where the risk of PTB increases as these measures worsen.
Recent work in this field has begun to examine the complex relationship between these measures and PTB, especially how other social determinants and behaviors may modify observed associations between a specific factor and PTB risk. A recent study by Braveman et al. (27) examined the complex relationship between socioeconomic status and racial disparities in PTB rates. This study linked comprehensive social determinant survey data to a large statewide population-based database, demonstrating a significant interaction between race and income, maternal education, and paternal occupation and racial disparities in the risk of PTB. This study found a reduction in the difference in preterm delivery rates between black and white women as community poverty and social depravation increased, with no measured difference when census tract-level poverty was above $25 \%$. In contrast, a study in Australia found that disparities in PTB between Aboriginals and non-Aboriginals were higher in more disadvantaged women compared to less disadvantaged women, where the gap was minimal (28). It is not clear from the literature why these studies found such different results. For racial discrimination, recent work from Chicago suggests that exposure to discrimination in the year prior to delivery was associated with a higher risk of PTB (OR: 2.5, 95\% CI: 1.2-5.2) than reports of exposure to racial discrimination throughout a woman's life (OR: 1.5, 
95\% CI: 0.9-2.8). Active coping skills helped to reduce these associations (29). Thus, while there have been multiple studies examining individual social determinant factors as potential explanatory factors for observed disparities in PTB, there have been limited studies accounting for multiple factors that elucidate the complex relationship that these factors may have on disparities in PTB.

\section{Community Factors}

As with individual socioeconomic factors, there have been numerous studies examining the association of community socioeconomic factors and preterm delivery. A systematic review of 106 studies showed a small to moderate association between increased preterm delivery rates and increased poverty, lower income, and higher measures of social depravation (17). For racial/ethnic differences in preterm delivery, studies have focused in two areas. First, studies stratify the racial/ethnic disparities in preterm delivery rates by levels of poverty and social depravation, such as the work of Braveman discussed in the previous section (27). Second, studies have performed racespecific regression models to examine the association between these community measures of poverty and preterm delivery risk. This body of work has found conflicting data. Many studies show an increased effect of community poverty on PTB risk for non-Hispanic black women compared to other racial/ethnic groups $(17,30-32)$, whereas other studies have found the opposite effect, specifically when studying the effect of racial/ ethnic group density on PTB risk (33). These studies all suggest that measured community factors have an effect on the risk of preterm delivery, but that the effect may differ between racial/ ethnic groups, similar to what has been demonstrated for the effects of individual-level social determinants.

There has been less work investigating the importance of community factors on observed racial/ethnic disparities in PTB rates. A study using data from Durham County and Wake County, NC from 1999-2001 assessed several community factors on a block level to obtain homogeneous measures of the community (34). These factors spanned the domains of income/poverty, educational attainment, employment, occupation, and housing. Individual socioeconomic factors such as age, education, marital status, and gravity directly explained $40-43 \%$ of the racial disparity in preterm delivery rates for this study. However, community factors independently explained $15 \%$ of the observed racial disparities in PTB, with smaller contributions to the higher risk of low birth weight (7-8\%) and small-for-gestational age (4-5\%) in black women included in this study. For PTB, these community factors had the largest effect on racial disparities in moderate PTB rate, explaining $20 \%$ of the disparity, compared to extremely preterm deliveries, where neighborhood explained $7-10 \%$ of the difference.

The role of community factors across the life course of a woman has been explored in several projects that utilize a unique, generationally-linked birth certificate dataset from Illinois. This work finds several important results. First, lifelong exposure to low-income communities, as assessed by the community income of the grandmother and mother at the times of their respective pregnancies, was associated with a higher rate of low birth weight deliveries regardless of race/ ethnicity. However, the population-attributable risk of LBW delivery from lifelong residence in low-income communities differed by race, with a population-attributable risk of $1.6 \%$ in non-Hispanic white women, vs. $23.6 \%$ in black women (35). Second, upward mobility, defined as women who resided in high-income communities during their pregnancy but were born in low-income communities, was associated with a lower risk of low birth weight in black women (36). Finally, increasing maternal age was associated with an increased risk of low birth weight only in black women with longer exposure to low income communities, such that the black women over the age of 30 had an odds ratio of 1.48-1.63 for low birth weight compared to black women under the age of 20. Black women with upward economic mobility, those who resided in high-income areas at both time points measured in this study, and white women did not experience such differential effect (12).

There are several studies examining the association between the risk of PTB and measures of racial segregation. Table 2 shows the five constructs that assess residential segregation $(37,38)$. Most of the existing literature examining the relationship between segregation and PTB uses the isolation construct. In black women, these studies have found a statistically significant association between residing in a more isolated area and PTB risk (39-42). White women living in these same highly isolated areas for black women did not experience the same increase in PTB risk as their black counterparts (43), which suggests that there may be variation in where white and black women reside within these highly isolated communities.

However, there have been few studies of the relationship between other measures of segregation and PTB risk; how different constructs of segregation may interact to influence PTB risk; and how other factors, such as built environment, may mediate these results. Two recent studies have begun to examine these areas. First, a study using US natality data from

Table 2. Constructs of racial segregation

\begin{tabular}{ll}
\hline Measure & Definition \\
\hline Isolation or exposure & $\begin{array}{l}\text { Exposure to other racial/ethnic groups: degree of potential contact with people of same racial/ethnic group. } \\
\text { Conceptualized as the likelihood of sharing a neighborhood with a member of another racial/ethnic group. }\end{array}$ \\
Unevenness & Similarities in the racial/ethnic distribution of adjacent neighborhoods \\
Clustering & Physical adjoinment of neighborhoods of the same racial/ethnic group within a given geographic area \\
Centralization & How close a neighborhood is to the center of an urban area or metropolitan statistical area \\
Concentration & Population density in a given neighborhood, or the amount of physical space a given racial/ethnic group occupies \\
\hline
\end{tabular}




\section{\begin{tabular}{l|l} 
Review & Lorch and Enlow
\end{tabular}}

2000 examined the influence of "hypersegregation" on PTB risk (44). In this study, hypersegregation was defined as living in an area that met the criteria for segregation in four of five of these constructs. Twenty-two US metropolitan areas (9\%) met these criteria, with $28 \%$ of births occurring in these areas. Black women residing in these areas had a $15 \%$ higher risk of PTB compared to black women residing in less segregated areas (areas who met the criteria for segregation in three or fewer constructs). This risk remained elevated after controlling for individual measures of socioeconomic status. As with studies using the isolation alone, white women residing in these hypersegregated areas did not have a statistically significant change in their risk of PTB. One other studies found that the isolation and clustering constructs act differently on PTB risk when assessed together: controlling for isolation, higher clustering was associated with a lower risk of PTB for black women (43). These studies suggest that different segregation constructs may assess different aspects of racial/ethnic segregation, with ensuing different effects on PTB risk.

The second recent study examined the importance of built environment assessed at the census block level on the association between residential segregation and PTB risk (45). The specific measures included housing damage; property damage; nuisances; home vacancy; crime; and percent home rentals. These built factors mediated $35 \%$ of the effect of racial/ethnic isolation on the risk of PTB. This study is important because, while changing racial/ethnic segregation may require a long time horizon, states and local governments may have more tools to combat poor built environment.

There are other limitations in the current state of this literature. First, the role of residential segregation and the built environment have not been examined for disparities in either the fetal or infant mortality rates. In the adult literature, residing in a higher segregated area is associated with a higher risk of mortality in conditions such as cancer (46) and diabetes (47). Second, most studies in this area use segregation indices from large geographic areas such as the metropolitan statistical area, which may not reflect what an individual woman experiences in her day-to-day activities. This potential misclassification is suggested by differences in the effect of segregation on PTB rates for women of different racial/ethnic status who reside in the same area. Finally, individual level experiences with racism and racial discrimination have not been examined concurrently with measures of community segregation for their combined effects on disparities in PTB.

\section{Physical Environment}

There are numerous studies of the association between environmental exposures and pregnancy outcomes. Specific exposures include fine particulate air particles, carbon monoxide, and ozone. Other studies examine the impact of residing near chemical plants, refineries, or other industries (48-59). There are also studies that suggest that racial/ethnic minorities are at greater likelihood of residing in communities with higher pollution rates, based on monitoring data from the Environmental Protection Agency (57). However, there are few studies formally examining whether these environmental exposures explain some of the observed racial/ethnic disparities in perinatal outcomes. One study examined this question using Natality data from 1998-1999 linked to an air pollution index at the county level (60). Hispanic women (OR: 4.66) and non-Hispanic black women (OR: 2.58) were more likely to reside in a region of increased air pollution. Air pollution was independently associated with higher rates of PTB, but could not explain disparities in PTB risk for either racial/ ethnic group. In contrast, a recently published study using particulate air pollutant data in Florida from 2000 to 2007 found an overall increased risk of PTB (OR: 1.12, 95\% CI: 1.06-1.18), low-birth-weight (OR: 1.18, 95\% CI: 1.11-1.25) and very-low-birth-weight deliveries (OR: 1.27, 95\% CI: $1.08-1.49$ ) in the $23.2 \%$ of total births that lived in a particulate exposed area. When the effect of exposure to particulate air pollution was examined in non-Hispanic white and black women separately, exposure to air pollution in black women was associated with a $68-300 \%$ higher increase odds of these adverse outcomes compared to white women exposed to particulate air pollution (61).

These studies show the challenges of studying environmental exposures as a mediating factor for racial/ethnic disparities in pregnancy outcomes. In most studies, the exposure data are taken from air pollution monitoring stations, with individual exposure extrapolated from the distance from these stations to a woman's residence. The accuracy of this assessment depends on the accuracy of residential data (zip code vs. physical address) in the dataset, and the assessment of other potential toxins.

\section{NEONATAL MORTALITY}

Black infants die twice as often as white infants (62), primarily through higher rates of PTB (63). A similar disparity is seen in the rate of postneonatal mortality (64). Although health behaviors, such as smoking, substance abuse, and receipt of prenatal care play a role in explaining these disparities, measures of individual sociodemographic status, including income, education and participation in the Special Supplemental Nutrition Program for Women, Infants, and Children (WIC), explain a larger portion of the disparities in mortality (65). However, black infants born to college-educated black parents die at nearly twice the rate of white infants born to college-educated white parents (63). Other potential factors that may reduce the disparity in neonatal mortality include adequate prenatal care $(66,67)$, participation in prenatal WIC $(68)$ and paternal involvement in childrearing (69).

Studies have also examined community factors to explain disparities in neonatal and infant mortality. Community factors explained almost $50 \%$ of the black-white disparity in postneonatal mortality rates in Chicago, with individual factors further explaining an additional $6-7 \%$ of the difference (70). However, in Milwaukee, using income data from residential zip codes, infant mortality rates remained elevated for black children until they resided in the highest income areas, while infant mortality rates for white children began to fall when 
they resided in middle income areas (71). This result is similar to newer work on PTB risk (27).

Other potential factors, such as experiences with discrimination, housing stock, or racial segregation, have not been examined. While there is this literature on potential explanatory factors for disparities in neonatal and postneonatal mortality, there have been no studies that formally evaluate any of the potential individual or community level mediating factors listed in Table 1.

\section{FETAL MORTALITY}

There are also substantial racial and ethnic disparities in the rate of fetal death with several studies demonstrating more than a twofold increase in risk among Black women (72-75). There have been, though, few studies of the role of either individual-level or community-level social determinants of health to explain this observed disparity. The best-studied factors are measures of individual socioeconomic status. Similar to PTB, disparities in fetal death are partially, but not completely, explained by these measures, the effect of which may differ between different racial/ethnic groups. For example, maternal age, education, and insurance status as a proxy of household income collectively explained $15 \%$ of the black-white disparity in fetal death and $35 \%$ of the disparity between Hispanic and non-Hispanic white women in multiple US states (74). Higher education is associated with a lower risk of stillbirth for both black and white women though the risk reduction is greater for white women (72). Other potential factors listed in Table 1 at all levels have not been formally examined.

\section{SUMMARY AND FUTURE RESEARCH NEEDS}

In summary, there is an extensive literature that supports the premise that social determinants may mediate or modify observed racial/ethnic differences in perinatal outcomes. The best-studied outcome is PTB risk. Fewer studies explore the mediating factors in the outcomes of fetal death, neonatal death, or postneonatal death, even though similar racial disparities exist for these outcomes. While individual factors are strong predictors of these differences in risk, they do not explain all of the disparity. Recent innovations in study design suggest an important contribution of community and environmental factors to these disparities.

There are a number of potential avenues for further research in this field. These avenues include:

\section{Improved Integration of Patient-Reported Outcomes in Population-Based Datasets}

Studies of perinatal outcomes require large datasets to be adequately powered for these rare outcomes. Many of the aforementioned social determinants, though, require patient report of data. The expansion of electronic health records for research purposes is a necessary step toward improving the data available for these studies. However, improved collection and recording of social determinant data within the electronic health record is also needed. Finally, methods to collect this information from patients in a patient-centered, culturally-competent manner are important in order to maintain patient trust and elicit accurate responses.

\section{Evaluating the Importance of Social Determinants Over the Life Course of the Woman}

Toxic stress and the weathering phenomenon are two theoretical constructs that underlie the differential risk of preterm delivery and other adverse perinatal outcomes in racial/ethnic minorities (13). There have been few studies that formally measure and test these hypotheses on a longitudinal level, especially for differences in fetal or infant mortality. These studies would require longitudinally linked data across generations and improved health information on patients as they move across state lines and/or change insurance plans in the United States (15).

\section{Inclusion of Other Potential Moderating or Mediating Factors Such as Access to Care and Care Quality}

Few studies formally evaluate how the effect of these various measures of social determinants are influenced by access to care and the quality of care patients can access. Living in a segregated area has been associated with the higher likelihood of adult black patients receiving surgery at low-quality hospitals (76) and a lower likelihood that black breast cancer patients receive adequate care quality (77). Early access to high-quality health care at points before, during, and after a pregnancy is another potential area for providers and policy makers to modify some of the adverse consequences of these social determinants of health. Racial/ethnic minorities are at higher risk of receiving care from poor providers, but how this factor relates to observed differences in perinatal outcomes is still not known $(78,79)$.

\section{Determining the Impact of Different Mechanisms for Each Adverse Outcome}

There are numerous mechanisms by which adverse pregnancy outcomes may occur. For example, PTB may result from spontaneous labor; premature rupture of membranes; or medical indications for maternal reasons among others. Similar heterogeneity also exists for fetal, neonatal, and postneonatal mortality. There are no studies that examine whether specific social determinants may influence the risk of a type of outcome, such as spontaneous PTB, and whether these relationships may better explain the observed racial/ethnic disparities in each adverse pregnancy outcome.

\section{Developing Epigenomic Pathways}

There are numerous mechanisms by which these social determinants of health may ultimate result in racial/ethnic disparities in perinatal outcomes. Some researchers have argued that epigenetic changes experienced by minority women may be a pathway that has not been fully explored (80). Such work requires careful collection of genetic and social determinant data within a large cohort of at-risk women.

Improved understanding of these pathways that underlie the large observed differences in adverse perinatal outcomes 
between women of different races is critical to developing programs to reduce and/or eliminate these disparities in health outcomes. Such innovative studies as those presented above are the first step toward the development of such work.

\section{STATEMENT OF FINANCIAL SUPPORT}

This study was supported by National Institutes of Health, R01HD057168, Bethesda, MD.

Disclosure: The authors have no financial relationships relevant to this article to disclose.

\section{REFERENCES}

1. Matthews TJ, MacDorman MF. Infant mortality statistics from the 2010 period linked birth/infant death data set. Natl Vital Stat Rep 2013;62:1-26.

2. MacDorman MF, Kirmeyer SE, Wilson EC. Fetal and perinatal mortality, United States, 2006. Natl Vital Stat Rep 2012;60:1-22.

3. Hamilton BE, Martin JA, Ventura SJ. Births: preliminary data for 2011. Natl Vital Stat Rep 2012;61:1-18.

4. World Health Organization. Social determinants of health: key concepts, 2015. http://www.who.int/social_determinants/thecommission/finalreport/key_concepts/en/

5. World Health Organization. Closing the gap in a generation: health equity through action on the social determinants of health. Final Report of the Commission on Social Determinants of Health, 2008. http://apps.who.int/ iris/bitstream/10665/43943/1/9789241563703_eng.pdf.

6. World Health Organziation. Closing the gap: policy into practice on social determinants of health: discussion paper, 2011. http://www.who.int/sdhconference/Discussion-Paper-EN.pdf.

7. Frieden TR; Centers for Disease Control and Prevention (CDC). Forward: CDC health disparities and inequalities report - United States, 2011. MMWR Surveill Summ 2011;60 Suppl:1-2.

8. Meyer PA, Yoon PW, Kaufmann RB; Centers for Disease Control and Prevention (CDC). Introduction: CDC Health Disparities and Inequalities Report - United States, 2013. MMWR Surveill Summ 2013;62 Suppl 3:3-5.

9. Kramer MR, Hogue CJ, Dunlop AL, Menon R. Preconceptional stress and racial disparities in preterm birth: an overview. Acta Obstet Gynecol Scand 2011;90:1307-16.

10. Holzman C, Eyster J, Kleyn M, et al. Maternal weathering and risk of preterm delivery. Am J Public Health 2009;99:1864-71.

11. Hogue CJ, Bremner JD. Stress model for research into preterm delivery among black women. Am J Obstet Gynecol 2005;192(5 Suppl):S47-55.

12. Love C, David RJ, Rankin KM, Collins JW Jr. Exploring weathering: effects of lifelong economic environment and maternal age on low birth weight, small for gestational age, and preterm birth in African-American and white women. Am J Epidemiol 2010;172:127-34.

13. Lu MC, Halfon N. Racial and ethnic disparities in birth outcomes: a lifecourse perspective. Matern Child Health J 2003;7:13-30.

14. Kramer MR, Williamson R. Multivariate Bayesian spatial model of preterm birth and cardiovascular disease among Georgia women: Evidence for life course social determinants of health. Spat Spatiotemporal Epidemiol 2013;6:25-35.

15. Kramer MR, Dunlop AL, Hogue CJ. Measuring women's cumulative neighborhood deprivation exposure using longitudinally linked vital records: a method for life course $\mathrm{MCH}$ research. Matern Child Health J 2014;18:478-87.

16. Spong CY, Iams J, Goldenberg R, Hauck FR, Willinger M. Disparities in perinatal medicine: preterm birth, stillbirth, and infant mortality. Obstet Gynecol 2011;117:948-55.

17. Blumenshine P, Egerter S, Barclay CJ, Cubbin C, Braveman PA. Socioeconomic disparities in adverse birth outcomes: a systematic review. Am J Prev Med 2010;39:263-72.

18. Lieberman E, Ryan KJ, Monson RR, Schoenbaum SC. Risk factors accounting for racial differences in the rate of premature birth. $\mathrm{N}$ Engl J Med 1987;317:743-8.

19. Cooperstock MS, Bakewell J, Herman A, Schramm WF. Association of sociodemographic variables with risk for very preterm birth in twins. Obstet Gynecol 1998;92:53-6.
20. El-Sayed AM, Tracy M, Galea S. Life course variation in the relation between maternal marital status and preterm birth. Ann Epidemiol 2012;22:168-74.

21. Mendez DD, Hogan VK, Culhane JF. Institutional racism, neighborhood factors, stress, and preterm birth. Ethn Health 2014;19:479-99.

22. Dominguez TP, Dunkel-Schetter C, Glynn LM, Hobel C, Sandman CA. Racial differences in birth outcomes: the role of general, pregnancy, and racism stress. Health Psychol 2008;27:194-203.

23. Collins JW Jr, David RJ, Handler A, Wall S, Andes S. Very low birthweight in African American infants: the role of maternal exposure to interpersonal racial discrimination. Am J Public Health 2004;94:2132-8.

24. Mustillo S, Krieger N, Gunderson EP, Sidney S, McCreath H, Kiefe CI. Selfreported experiences of racial discrimination and Black-White differences in preterm and low-birthweight deliveries: the CARDIA Study. Am J Public Health 2004;94:2125-31.

25. Dole N, Savitz DA, Hertz-Picciotto I, Siega-Riz AM, McMahon MJ, Buekens P. Maternal stress and preterm birth. Am J Epidemiol 2003;157:14-24.

26. Tucker CM, Berrien K, Menard MK, et al. Predicting preterm birth among women screened by North Carolina's pregnancy medical home program. Matern Child Health J 2015;19:2438-52.

27. Braveman PA, Heck K, Egerter S, et al. The role of socioeconomic factors in Black-White disparities in preterm birth. Am J Public Health 2015;105:694-702.

28. Langridge AT, Nassar N, Li J, Stanley FJ. Social and racial inequalities in preterm births in Western Australia, 1984 to 2006. Paediatr Perinat Epidemiol 2010;24:352-62.

29. Rankin KM, David RJ, Collins JW Jr. African American women's exposure to interpersonal racial discrimination in public settings and preterm birth: the effect of coping behaviors. Ethn Dis 2011;21:370-6.

30. Messer LC, Kaufman JS, Dole N, Savitz DA, Laraia BA. Neighborhood crime, deprivation, and preterm birth. Ann Epidemiol 2006;16:455-62.

31. Kaufman JS, Dole N, Savitz DA, Herring AH. Modeling community-level effects on preterm birth. Ann Epidemiol 2003;13:377-84.

32. Pickett KE, Ahern JE, Selvin S, Abrams B. Neighborhood socioeconomic status, maternal race and preterm delivery: a case-control study. Ann Epidemiol 2002;12:410-8.

33. Masi CM, Hawkley LC, Piotrowski ZH, Pickett KE. Neighborhood economic disadvantage, violent crime, group density, and pregnancy outcomes in a diverse, urban population. Soc Sci Med 2007;65:2440-57.

34. Schempf AH, Kaufman JS, Messer LC, Mendola P. The neighborhood contribution to black-white perinatal disparities: an example from two north Carolina counties, 1999-2001. Am J Epidemiol 2011;174:744-52.

35. Collins JW Jr, Wambach J, David RJ, Rankin KM. Women's lifelong exposure to neighborhood poverty and low birth weight: a population-based study. Matern Child Health J 2009;13:326-33.

36. Collins JW Jr, Rankin KM, David RJ. African American women's lifetime upward economic mobility and preterm birth: the effect of fetal programming. Am J Public Health 2011;101:714-9.

37. Massey DS, Denton NA. The dimensions of residential segregation. Soc Forces 1988;67:281-315.

38. Massey DS, Denton NA. Hypersegregation in U.S. metropolitan areas: black and Hispanic segregation along five dimensions. Demography 1989;26:373-91.

39. Grady SC. Racial disparities in low birthweight and the contribution of residential segregation: a multilevel analysis. Soc Sci Med 2006;63:3013-29.

40. Grady SC, Ramírez IJ. Mediating medical risk factors in the residential segregation and low birthweight relationship by race in New York City. Health Place 2008;14:661-77.

41. Bell JF, Zimmerman FJ, Almgren GR, Mayer JD, Huebner CE. Birth outcomes among urban African-American women: a multilevel analysis of the role of racial residential segregation. Soc Sci Med 2006;63:3030-45.

42. Messer LC, Oakes JM, Mason S. Effects of socioeconomic and racial residential segregation on preterm birth: a cautionary tale of structural confounding. Am J Epidemiol 2010;171:664-73.

43. Kramer MR, Cooper HL, Drews-Botsch CD, Waller LA, Hogue CR. Metropolitan isolation segregation and Black-White disparities in very preterm birth: a test of mediating pathways and variance explained. Soc Sci Med 2010;71:2108-16. 
44. Osypuk TL, Acevedo-Garcia D. Are racial disparities in preterm birth larger in hypersegregated areas? Am J Epidemiol 2008;167:1295-304.

45. Anthopolos R, Kaufman JS, Messer LC, Miranda ML. Racial residential segregation and preterm birth: built environment as a mediator. Epidemiology 2014;25:397-405.

46. Pruitt SL, Lee SJ, Tiro JA, Xuan L, Ruiz JM, Inrig S. Residential racial segregation and mortality among black, white, and Hispanic urban breast cancer patients in Texas, 1995 to 2009. Cancer 2015;121:1845-55.

47. Rosenstock S, Whitman S, West JF, Balkin M. Racial disparities in diabetes mortality in the 50 most populous US cities. J Urban Health 2014;91: 873-85.

48. Padula AM, Noth EM, Hammond SK, et al. Exposure to airborne polycyclic aromatic hydrocarbons during pregnancy and risk of preterm birth. Environ Res 2014;135:221-6.

49. Porter TR, Kent ST, Su W, Beck HM, Gohlke JM. Spatiotemporal association between birth outcomes and coke production and steel making facilities in Alabama, USA: a cross-sectional study. Environ Health 2014;13:85.

50. Gehring U, Tamburic L, Sbihi H, Davies HW, Brauer M. Impact of noise and air pollution on pregnancy outcomes. Epidemiology 2014;25:351-8.

51. Vadillo-Ortega F, Osornio-Vargas A, Buxton MA, et al. Air pollution, inflammation and preterm birth: a potential mechanistic link. Med Hypotheses 2014;82:219-24.

52. Candela S, Ranzi A, Bonvicini L, et al. Air pollution from incinerators and reproductive outcomes: a multisite study. Epidemiology 2013;24:863-70.

53. Huppé V, Kestens Y, Auger N, Daniel M, Smargiassi A. Residential proximity to gasoline service stations and preterm birth. Environ Sci Pollut Res Int 2013;20:7186-93.

54. Mainolfi MB, Salihu HM, Wilson RE, Mbah AK. Low-level exposure to air pollution and risk of adverse birth outcomes in Hillsborough County, Florida. J Occup Environ Med 2013;55:490-4.

55. Ghosh JK, Wilhelm M, Ritz B. Effects of residential indoor air quality and household ventilation on preterm birth and term low birth weight in Los Angeles County, California. Am J Public Health 2013;103:686-94.

56. Zeka A, Melly SJ, Schwartz J. The effects of socioeconomic status and indices of physical environment on reduced birth weight and preterm births in Eastern Massachusetts. Environ Health 2008;7:60.

57. Ritz B, Wilhelm M, Hoggatt KJ, Ghosh JK. Ambient air pollution and preterm birth in the environment and pregnancy outcomes study at the University of California, Los Angeles. Am J Epidemiol 2007;166:1045-52.

58. Ponce NA, Hoggatt KJ, Wilhelm M, Ritz B. Preterm birth: the interaction of traffic-related air pollution with economic hardship in Los Angeles neighborhoods. Am J Epidemiol 2005;162:140-8.

59. Wilhelm M, Ritz B. Residential proximity to traffic and adverse birth outcomes in Los Angeles county, California, 1994-1996. Environ Health Perspect 2003;111:207-16.

60. Woodruff TJ, Parker JD, Kyle AD, Schoendorf KC. Disparities in exposure to air pollution during pregnancy. Environ Health Perspect 2003;111: 942-6.

61. Salihu HM, Ghaji N, Mbah AK, Alio AP, August EM, Boubakari I. Particulate pollutants and racial/ethnic disparity in feto-infant morbidity outcomes. Matern Child Health J 2012;16:1679-87.
62. Mathews TJ, MacDorman MF. Infant mortality statistics from the 2007 period linked birth/infant death data set. Natl Vital Stat Rep 2011;59:1-30.

63. Schoendorf KC, Hogue CJ, Kleinman JC, Rowley D. Mortality among infants of black as compared with white college-educated parents. N Engl J Med 1992;326:1522-6.

64. Hauck FR, Tanabe KO, Moon RY. Racial and ethnic disparities in infant mortality. Semin Perinatol 2011;35:209-20.

65. Finch BK, Frank R, Hummer RA. Racial/ethnic disparities in infant mortality: the role of behavioral factors. Soc Biol 2000;47:244-63.

66. Byrd DR, Katcher ML, Peppard P, Durkin M, Remington PL. Infant mortality: explaining black/white disparities in Wisconsin. Matern Child Health J 2007;11:319-26.

67. Kitsantas P, Gaffney KF. Racial/ethnic disparities in infant mortality. J Perinat Med 2010;38:87-94.

68. Khanani I, Elam J, Hearn R, Jones C, Maseru N. The impact of prenatal WIC participation on infant mortality and racial disparities. Am J Public Health 2010;100 Suppl 1:S204-9.

69. Ngui EM, Cortright AL, Michalski K. Relationship of Paternity Status, Welfare Reform Period, and Racial/Ethnic Disparities in Infant Mortality. Am J Mens Health 2015;9:350-9.

70. Collins JW Jr, Hawkes EK. Racial differences in post-neonatal mortality in Chicago: what risk factors explain the black infant's disadvantage? Ethn Health 1997;2:117-25.

71. Ward TC, Mori N, Patrick TB, Madsen MK, Cisler RA. Influence of socioeconomic factors and race on birth outcomes in urban Milwaukee. WMJ 2010;109:254-60.

72. Willinger M, Ko CW, Reddy UM. Racial disparities in stillbirth risk across gestation in the United States. Am J Obstet Gynecol 2009;201:469.e1-8.

73. Gold KJ, DeMonner SM, Lantz PM, Hayward RA. Prematurity and low birth weight as potential mediators of higher stillbirth risk in mixed black/ white race couples. J Womens Health (Larchmt) 2010;19:767-73.

74. Lorch SA, Kroelinger CD, Ahlberg C, Barfield WD. Factors that mediate racial/ethnic disparities in US fetal death rates. Am J Public Health 2012;102:1902-10.

75. Hogue CJ, Parker CB, Willinger M, et al.; Eunice Kennedy Shriver National Institute of Child Health and Human Development Stillbirth Collaborative Research Network Writing Group. A population-based case-control study of stillbirth: the relationship of significant life events to the racial disparity for African Americans. Am J Epidemiol 2013;177:755-67.

76. Dimick J, Ruhter J, Sarrazin MV, Birkmeyer JD. Black patients more likely than whites to undergo surgery at low-quality hospitals in segregated regions. Health Aff (Millwood) 2013;32:1046-53.

77. Haas JS, Earle CC, Orav JE, et al. Racial segregation and disparities in breast cancer care and mortality. Cancer 2008;113:2166-72.

78. Jha AK, Orav EJ, Epstein AM. Low-quality, high-cost hospitals, mainly in South, care for sharply higher shares of elderly black, Hispanic, and medicaid patients. Health Aff (Millwood) 2011;30:1904-11.

79. Bach PB, Pham HH, Schrag D, Tate RC, Hargraves JL. Primary care physicians who treat blacks and whites. N Engl J Med 2004;351:575-84.

80. Burris HH, Collins JW Jr. Race and preterm birth-the case for epigenetic inquiry. Ethn Dis 2010;20:296-9. 